\title{
Metacarpal Bone Digit 3
}

National Cancer Institute

\section{Source}

National Cancer Institute. Metacarpal Bone Digit 3. NCI Thesaurus. Code C52794.

The third of five miniature long bones located in the palm of the hand, which articulates proximally with the capitate and second and fourth metacarpals at the carpometacarpal joint and distally with the middle fing er phalanx at the metacarpophalangeal joint. 